\title{
Литология и фации ястребовских отложений присводовой части Воронежской антеклизы
}

\author{
¡ 2020 А. В. Милаш ${ }^{\bowtie}$ \\ Воронежский государственный университет, \\ Университетская пл., 1, 394018, Воронеж, Российская федерация
}

\begin{abstract}
Аннотация
Введение: Статья посвящена изучению вещественного состава ястребовских отложений раннего франа присводовой части Воронежской антеклизы, а также характеристике составленных литолого-фациальных карт масштаба 1:200 000 и схем седиментогенеза.

Методика: В ходе работы основным методом исследования был литолого-фациальный анализ. В результате изучения каменного материала и на основании описания скважин выделялись литогенетические типы отложений, использованные при построении фациальных карт.

Результаты и обсуждения: В результате подробной литологической характеристики основных типов ястребовских образований, показано, что формирование исследуемых осадков практически на всей исследуемой территории происходило в прибрежно-морских и мелководно-морских условиях со слабой и средней активностью гидродинамического режима, а на юго-востоке Воронежской антеклизы - в лагунных и дельтовых условиях. Определяющим фактором осадконакопления на юго-востоке территории являлась эксплозивная вулканическая деятельность.

Заключение: Ястребовские отложения формировались в условиях теплого гумидного климата при малоамплитудных тектонических движениях. В это время море трансгрессировало с востока, а с юга и запада шел снос терригенного материала. Характерной особенностью ястребовских образований является примесь в них пирокластического материала на юго-востоке территории, поступавшего из действующих вулканов. Данные результаты могут быть использованы при проведении геологосъемочных работ на исследуемой территории и стать основой для литолого-фациального картирования масштаба 1:200 000 всей территории Воронежской антеклизы.

Ключевые слова: фациальный анализ, схема седиментогенеза, ястребовское время, прибрежноморская фациальная зона, мелководно-морская фациальная зона, лагуна, дельта, вулканогенноосадочные породы, ильменит.
\end{abstract}

Источник финансирования: Исследование выполнено при финансовой поддержке РФФИ в рамках научного проекта № 18-35-00115 мол_а.

Для циитирования: Милаш А. В. Литология и фации ястребовских отложений присводовой части Воронежской антеклизы // Вестник Воронежского государственного университета. Серия: Геология. 2020. №1. С. 59-65. DOI: https://doi.org/10.17308/geology.2020.1/2514

\section{Введение}

На исследуемой территории образования ястребовского времени развиты практически повсеместно. Они с размывом залегают на отложениях ардатовской и муллинской свит, в единичных разрезах на докембрийс- ских образованиях, перекрываются чаплыгинской свитой, меловыми или четвертичными отложениями. [1-3].

Ястребовская свита впервые была выделена как «алевритово-каолиновая» пачка в основании

\section{Контент доступен под лицензией Creative Commons Attribution 4.0 License.}

\footnotetext{
${ }^{凶}$ Милаш Алексей Васильевич, E-mail: pirit86@yandex.ru
} 
нижнещигровских отложений В. Н. Преображенской в 1954 г. в районе Старого Оскола и Тима. В 1955 г. А. И. Ляшенко и С. В. Тихомиров выделили эти отложения в горизонт со стратотипом у с. Ястребовка у г. Старый Оскол. Принадлежность ястребовской свиты к верхнему девону установлена В. Т. Умновой (1967) и Л. Г. Раскатовой (1969) по споровым комплексам [4].

Разрез ястребовской свиты, в целом, характеризуется переслаиванием песчаников, алевролитов и глин, в большинстве районов содержащих оолиты гидрогетит-сидерит-лептохлоритового состава. На юговостоке исследуемой территории наиболее распространены, как по площади, так и в разрезе, песчаники, среди которых по составу можно выделить три типа: слюдисто-кварцевые, олигомиктовые и вулканомиктовые. Аргиллитоподобные глины и алевриты распространены преимущественно в мелководноморской зоне, в прибрежно-морских условиях они наблюдаются в виде маломощных линз. В центральной и северной частях территории преобладающими породами являются алевриты и, в меньшей степени, глины, а песчаники распространены только у границы выклинивания отложений. Глины по составу преимущественно каолинитовые, в отдельных разрезах в заметных количествах присутствует хлорит [5]. Мощность отложений колеблется от первых метров у границы выклинивания до 40 м на севере территории.

Данное время ознаменовалось проявлением эксплозивной вулканической деятельности в южной части исследуемой площади, которая оказала существенное влияние на осадконакопление и определила особенный облик пород ястребовской свиты. Ястребовские образования здесь характеризуются наличием в разрезе вулканогенно-обломочных пород, наиболее грубые разности которых (средне- и крупнообломочные туфы, туфобрекчии, туфоконгломераты), накапливались вокруг центров извержений. Вулканогеннообломочные породы распространены в зоне ЛосевскоМамонского разлома и оперяющих его нарушений, где наблюдаются в виде линз среди нормальноосадочных отложений [6]. Для разреза характерно чередование этих пород с нормально-осадочными отложениями - разнозернистыми до грубозернистых песчаниками, алевролитами и аргиллитами.

Статья решает проблему реконструкции условий осадконакопления в ястребовское время на присводовой части Воронежской антеклизы. Выполненные литолого-фациальные построения позволили установить полифациальность ястребовских образований, определить границы фациальных обстановок, гидродинамические режимы, направление переноса обломочного материала, удаленность источников сноса, смену фаций по площади.

\section{Методика фациальных построений}

Составление фациальных карт проводилось в два этапа: подготовительный и составительский. В подготовительный этап вёлся сбор и систематизация всего фактического материала, его обработка для составле- ния карт. В составительский этап в определенной последовательности и в соответствии с фактическим материалом отрабатывался наиболее оптимальный вариант модели карты. Проводились следующие операции по составлению карты: 1. Нанесение на карту точек выбранных разрезов и мощности (полной или неполной) отложений изучаемого стратиграфического интервала; 2. Построение карты изопахит - линий равных мощностей; 3. Выделение фациальных зон.

Метод литолого-фациального исследования заключался в комплексном изучении отложений, отражающих особенности седиментации. Изучались структурно-текстурные признаки, характеризующие динамику среды и способ осадконакопления, состав фауны, наличие авто- и аллохтонного органического вещества, свидетельствующего о глубине бассейна и близости континента, состав минеральных компонентов, отражающих источники сноса материала. Затем определялась принадлежность литотипов пород к группам фаций: I-III - морские; IV - переходные. В каждой из групп выделялись фациальные обстановки по типу гидродинамического режима в бассейне седиментации (для морских образований) и по типам обстановок (для переходных отложений). Полные разрезы с установленными кровлей и подошвой стратиграфического подразделения (горизонта), принимались за 100\%. Затем проводился подсчет процентного соотношения мощностей различных литотипов в разрезах. При этом породы, слагающие менее $10 \%$ всего разреза, на картах не показаны. Границы резких изменений состава и типов пород в плане и в разрезе соответствуют границам фациальных зон. Литология пород показывается соответствующим знаком, фациальная обстановка - римской цифрой. Последовательность полос снизу вверх в элементарном разрезе отвечает хронологической последовательности наслоения пород в каждом стратиграфическом подразделении. В соответствии с этим давались названия зон: первые цифры обозначают фациальную обстановку, буквы гидродинамический режим. При чередовании нескольких литотипов в разрезе, между цифровыми индексами, обозначающими фациальные обстановки, ставится тире. В случае невозможности установления однозначного генезиса различных типов отложений, используется двойной индекс. [7-9].

\section{Фациальные обстановки ястребовского времени}

На фациальной карте (рис. 1) ястребовского времени выделяется ряд зон прибрежной и мелководноморской частей морского бассейна, а так же переходных зон от морского бассейна к континенту.

Западнее г. Павловска и вдоль всей границы распространения отложений фрагментарно отмечаются зоны ІІІБ, связанные с локальными поднятиями доястребовского рельефа. Разрез в них представлен песчаниками светло-серыми, слюдисто-кварцевыми, с примесью полевых шпатов, на юге исследуемой территории полевошпат-кварцевыми. Песчаники мелкосреднезернистые с глинистым (каолинитовым или 

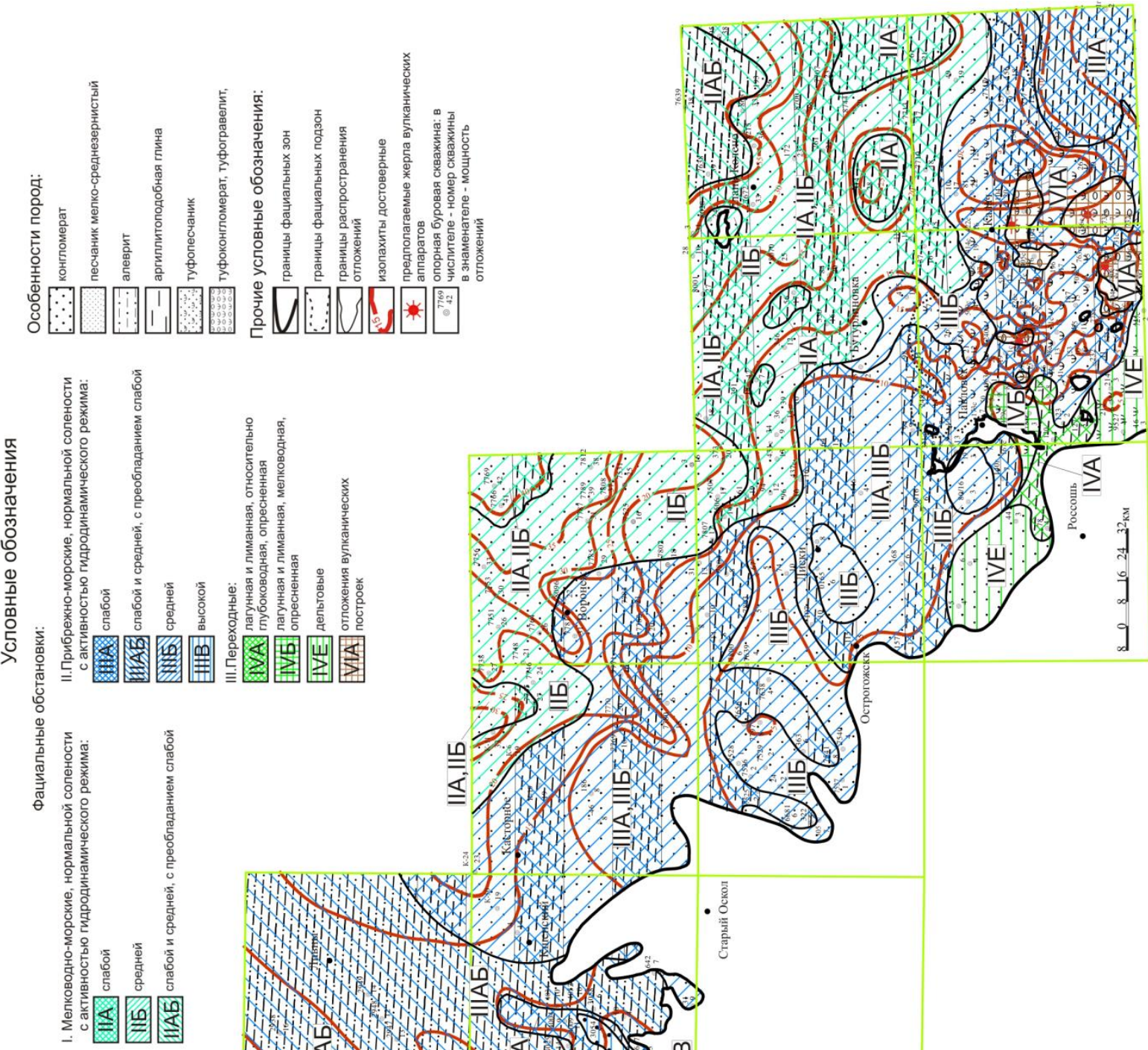
иллит-каолинитовым) и известково-глинистым цементом. Данные отложения в районе г. Павловска содержат пепловый материал.

В центральной части территории, у границы выклинивания ястребовских отложений отмечается зона IIIB, которая указывает на высокую гидродинамику среды в прибрежной части ястребовского моря. Отложения данной зоны представлены серыми грубозернистыми кварцевыми песчаниками с линзами переотложенных конгломератовидных железных руд.

На юго-востоке исследуемой территории, вдоль границы распространения отложений наблюдаются две фациальные зоны, представляющие собой конусы выноса речных отложений (зоны IVE). Породы в них представлены песчаниками (первые метры) зеленовато-серыми до темно-зеленых, разнозернистыми, от мелко- до крупнозернистых, косослоистыми, сцементированными глинисто-хлоритовой массой в фациальной зоне восточнее г. Россошь, и имеющие глинистый цемент в зоне расположенной севернее. В песчаниках присутствует большое количество УРО.

Между двумя конусами выноса в ястребовское время находилась лагуна (IVA), в которой формировались аргиллитоподобные иллит-каолинитовые глины серые, темно-серые в нижней части темно-бурые, с брекчиевидной текстурой и вкрапленностью сульфидов, плотные, тонкоплитчатые, со слабой горизонтальной слоистостью, жирные, с частыми углефицированными растительными остатками и пиритом.

Северо-восточнее зоны IVA располагается зона IVБ, представляющая собой бар или барьерный остров. Отложения в данной зоне представлены песчаником (до 5 м) кварц-вулканомиктовым, зеленоватосерым с прослоями грязно-зеленого песчаника, горизонтальнослоистым, мелкозернистым с глинистым цементом, с тонкорассеянным ильменитом, с УРО в виде стеблей растений.

Севернее зоны IVБ располагается зона IIIA, IIIБ. Данная зона занимает значительную площадь и тянется параллельно границе распространения отложений от с. Верхний Мамон на юге исследуемой территории до пгт. Касторное в центральной ее части. Разрез данной зоны представлен переслаиванием песчаников и аргиллитоподобных глин с подчиненным содержанием алевролита. Песчаники светло-серые, слюдистокварцевые, мелко-среднезернистые с глинистым (каолинитовым или иллит-каолинитовым) и известковоглинистым цементами. Глина серая с зеленоватым и буроватым оттенком, тонколистоватая, слабоалевритистая, с плохо выраженной горизонтальной слоистостью, изредка с присыпками песка кварцевого, слегка слюдистого по слоистости. На юго-востоке зоны, между г. Павловск, г. Калач и с. Верхний Мамон, выделяется подзона, отличающаяся наличием пеплового материала в песчаниках. Общая мощность пород до 20 м.

В вышеописанной фациальной зоне можно наблюдать участки с максимальными мощностями и наибольшей размерностью вулканогенно-обломочных пород, локализованных в виде разобщенных полей изометричной формы вблизи разломов, где существовали вулканические аппараты. Это зоны VIA, которые весьма подробно описаны авторами работы [5].

В разрезе зоны IIIA, расположенной на юговостоке исследуемой территории, преобладают аргиллитоподобные глины, а песчаники и алевролиты занимают подчиненное положение (не более $10 \%$ от мощности разреза). Глины аргиллитоподобные, серые, голубовато-серые, зеленовато-серые, с мелкими кристаллами сидерита и углефицированной органикой. Верх разреза венчают прослои среднезернистого песчаника с глинистым цементом. Глины сильно изрыты ходами илороющих организмов, заполненными мелкозернистым глинистым песчаником.

На северо-востоке от зоны ІІІА, ІІІБ, между г. Бутурлиновка и с. Елань-Колено, находится зона IIA, ІІБ. Отложения в данной зоне представлены аргиллитами, песчаниками и алеврито-глинистыми породами, образовавшимися в мелководно-морских условиях слабой (IIA), а также средней гидродинамической среды (ІІБ). В основном это тонко-мелкозернистые слюдисто-кварцевые пески, полимиктовые песчаники и алевролиты с прослоями глин (аргиллитов). Часто преобладающую роль в разрезе занимают аргиллиты. Влияние ястребовского вулканизма здесь было минимальным [10]. Частое переслаивание разных типов пород свидетельствует о периодических изменениях уровня бассейна. Здесь можно выделить ряд зон, связанных с локальными поднятиями и впадинами доястребовского рельефа. Впадины (зоны IIA), в основном, расположены вдоль южной границы фациальной зоны IIA, ІІБ. В них разрез сложен только аргиллитоподобными глинами с подчиненным содержанием алевролитов. Мощность глин во впадинах достигает 28 м. Поднятие (зона ІІБ) расположено на северезападе от с. Елань-Колено. Разрез в данной зоне представлен тонко-мелкозернистыми слюдисто-кварцевыми песчаниками, мощностью до 24 м.

Северо-восточнее с. Елань-Колено расположена зона ІІАБ. В ястребовское время на данной территории находилась впадина. Разрез представлен аргиллитоподобными глинами, коричневыми, плитчатыми, часто обогащенными железистыми оолитами, содержащими маломощные прослои алевритистых глин темно-серых, черных тонко-горизонтальнослоистых.

Максимальную площадь исследуемой территории занимает зона ІІІАБ, отложения которой сформировались в прибрежно-морских условиях со слабой и средней с преобладанием слабой активностью гидродинамического режима. Она расположена в районе г. Ливны, севернее г.г. Курска, Севска и Железногорска. Разрез практически нацело сложен пестроцветными алевритами - зеленовато-серыми, желтовато-серыми, желтовато-бурыми, кирпично-красными, плотными, глинистыми, с прослоями и линзами глин.

На северо-западе рассматриваемой площади, юговосточнее г. Брянска, в ястребовское время располагалась обширная впадина (зона IIA) в которой накапливались пестроцветные, красновато-коричневые, 
желтовато-зеленовато-серые, глины, плотные, неслоистые, жирные, аргиллитоподобные, слюдистые, в различной степени алевритистые и песчанистые. В глинах редко встречаются тонкие прослои алевритов.

В районе г.г. Малоархангельска и Брянска располагаются зоны IIIАБ,ІІА, отложения в которых представлены ритмичным переслаиванием алевритов и аргиллитоподобных глин описанных выше.

\section{Заключение}

Ястребовские отложения присводовой части Воронежской антеклизы формировались в лагунных и прибрежно-морских условиях, а также в относительно удаленных от берега участках дна чрезвычайно мелководного эпиконтинентального морского бассейна под влиянием климата, вулканизма и тектоники. Максимальное разнообразие фациальных обстановок характерно для юго-восточной части исследуемой территории (рис. 2). Рассматривая фациальные карты и схемы седиментогенеза, можно с уверенностью сказать, что в ястребовское время море двигалось с востока, северо-востока, а снос материала шел с юга и запада. Судя по составу ястребовских отложений, область сноса была сложена интенсивно выветрелыми среднедевонскими осадочными и докембрийскими кристаллическими породами. Характерной особенностью ястребовских образований на юго-востоке исследуемой территории является примесь в них пирокластического материала, поступавшего из действующих вулканов.

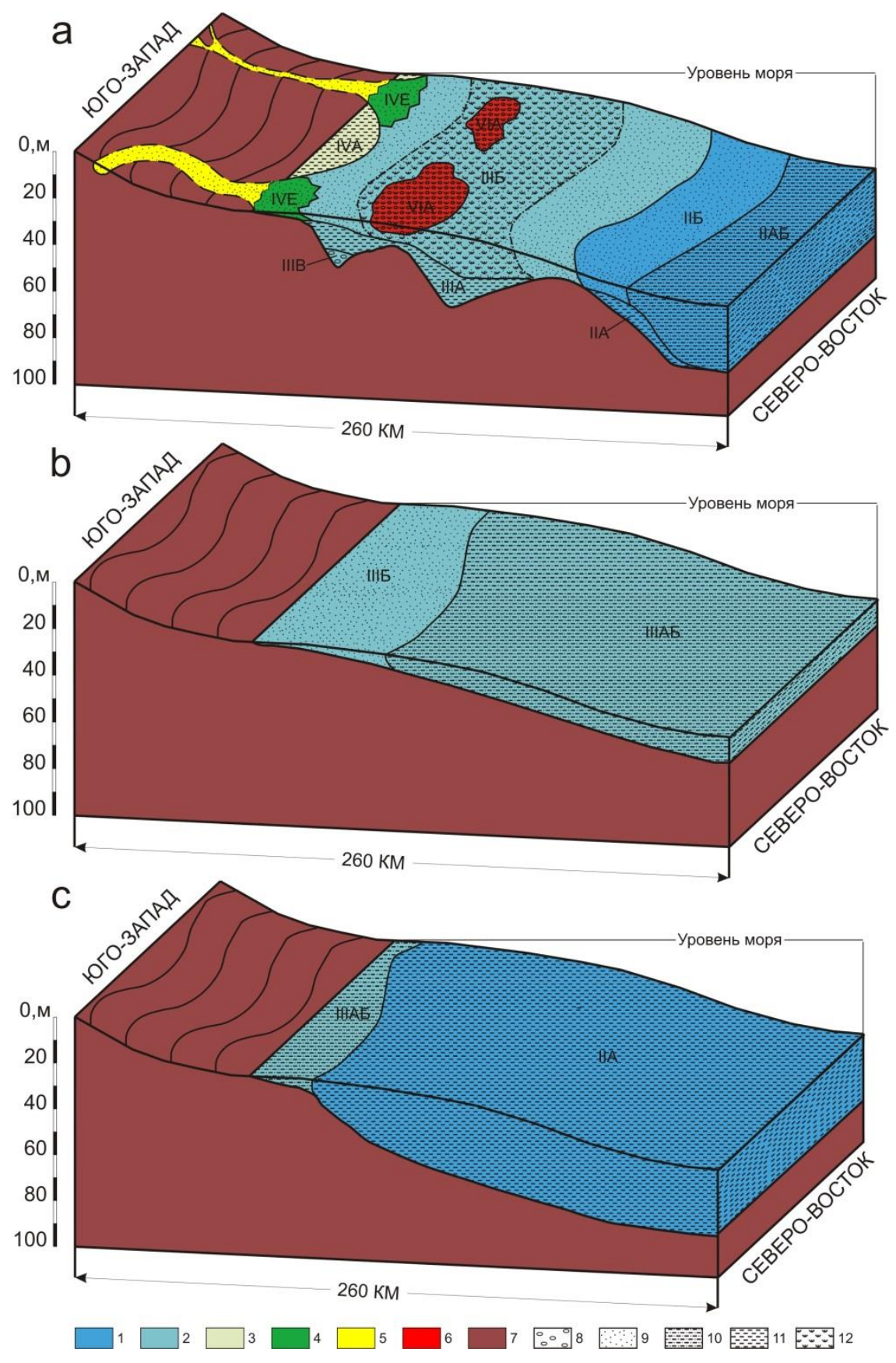

Рис. 2. Схемы седиментогенеза в ястребовское время для юговосточной (a), центральной (b) и северо-западной (c) части исследуемой территории: 1 - мелководноморские фациальные обстановки; 2 прибрежно-морские фациальные обстановки; 3 - лагунные фациальные обстановки; 4 - дельтовые фациальные обстановки; 5 - русловые фациальные обстановки; 6 - отложения вулканических построек; 7 область сноса; 8 - галечники; 9 пески и песчаники мелкосреднезернистые; 10 - глинистые алевриты и алевролиты; 11 - аргиллитоподобные глины; 12 - примесь туфогенного материала.

[Fig. 2. Schemes of sedimentogenesis in Jastrebovsky time for the southeastern (a), central (b) and northwestern (c) parts of the study area: 1 - shallow marine facies environments; 2 - coastal marine facies environments; 3 - lagoon facies environments; 4 - delta facies environments; 5 - channel facies environments; 6 - deposits of volcanic structures; 7 - demolition area; 8 - gravels; 9- sands and sandstones fine-grained; 10 - clayey siltstone and siltstone; 11 argillite; 12 - admixture of tufogenic material.] 
Конфликт интересов: Автор декларирует отсутствие явных и потенциальных конфликтов интересов, связанных с публикацией настоящей статьи.

\section{ЛИТЕРАТУРА}

1. Милаш А. В. Литолого-фациальная характеристика ястребовских отложений юго-востока Воронежской антеклизы // Вестник Воронежского государственного университета. Серия: Геология. 2016. № 1. С. 37-43. URL: http://www.vestnik.vsu.ru/pdf/heologia/2016/01/2016-01-05.pdf (дата обращения: 14.02.2020)

2. Савко А. Д., Мануковский С. В., Мизин А. И, Бурыкин В. Н., Бартенев В. К., Окороков В. А., Бабкин В. Ф. Литология и фации донеогеновых отложений Воронежской антеклизы. Труды научно-исследовательского института геологии: Воронеж, Изд-во Воронеж. гос. ун-та. Вып. 3 , 2001. 201 c. URL: http://ниигвгу.pф/nauchnye-trudy/trudyniig/ (дата обращения: 14.02.2020)

3. Савко А. Д. Геология Воронежской антеклизы. Труды научно-исследовательского института геологии : Воронеж, Изд-во Воронеж. гос. ун-та. Вып. 12, 2002. 165 с. URL: http://ниигвгу.pф/nauchnye-trudy/trudy-niig/ (дата обращения: 14.02.2020)

4. Кононова Л. И., Овнатова Н. С., Ржосницкая М. А., Родионова Г. Д., Умнова В. Т., Федорова Т. И. Девон Воронежской антеклизы и Московской синеклизы. М. : Комитет РФ по геологии и использованию недр, 1995. 265 с. URL: http://www.geokniga.org/books/7307 (дата обращения: 14.02.2020)

5. Милаш А. В., Савко А. Д. Литология девонских отло- жений юго-востока Воронежской антеклизы Труды научноисследовательского института геологии: Воронеж, Изд-во Воронеж. гос. ун-та. Вып. 100, 2017. 131 с. URL: https://www.elibrary.ru/item.asp?id=30314171 (дата обращения: 14.02.2020)

6. Канцеров В. А. Ильменитоносные вулканогенноосадочные породы позднего девона юго-востока Воронежской антеклизы: автореф. дис. ... канд. геол.-мин. наук: Харьков, 1984. - 23 с.

7. Савко А. Д., Мануковский С. В., Мизин А. И., Бурыкин В. Н., Бартенев В. К. Объяснительная записка к атласу фациальных карт Воронежской антеклизы. Труды научноисследовательского института геологии: Воронеж, Изд-во Воронеж. гос. ун-та. Вып. 20, 2004. 107 с. URL: http://ниигвгу.pф/nauchnye-trudy/trudy-niig/ (дата обращения: 14.2.2020)

8. Виноградов А. П., Наливкин В. Д., Ронов А. Б., Хаин В. Е. Атлас литолого-палеогеографических карт Русской платформы и ее геосинклинального обрамления. М.-Л.: Государственное научно-техническое издательство литературы по геологии и охране недр, 1961.c. 65-69.

9. Hallam A. Facies interpretation and the stratigraphic record. W. H. Freeman and Co. Oxford. 1981. 304 pp.

10. Милаш А.В. Проявление вулканизма в позднем девоне на юго-востоке Воронежской антеклизы. Актуальные проблемы динамической геологии при исследовании платформенных областей. Труды всероссийской научной конференции. Москва, 24-26 мая 2016 г. с. 92-94. URL: https://istina.msu.ru/collections/21179029/ (дата обращения: 14.02.2020)

UDC 551.83(470.32)

ISSN 1609-0691

DOI: https://doi.org/10.17308/geology.2020.1/2514

Received: 17.02 .2020

Accepted: 20.02.2020

Published online: 25.03 .2020

\title{
Lithology and facies of the Yastrebovsk deposits of the crestal part of the Voronezh Anteclise
}

\author{
(C) 2020 A. V. Milash ${ }^{\bowtie}$ \\ Voronezh State University, 1 Universitetskaya pl., Voronezh 394018, Russian Federation
}

\begin{abstract}
Introduction: This article is devoted to the study of the material composition of the Yastrebovsk deposits of the early Frasnian age of the crestal part of the Voronezh Anteclise and the characterization of the compiled lithological-facie maps of a scale of 1:200 000 and sedimentogenesis schemes.

Methodology: In the course of the work, the main research method was lithological-facies analysis. As a result of studying the stone material and based on the description of the wells, lithogenetic types of sediments used for the construction of facie maps were identified.

Results and discussions: As a result of a detailed lithological characterization of the main types of Yastrebovsk deposits, it was shown that the formation of the studied sediments over almost the entirety of the
\end{abstract}


studied territory occurred under coastal-marine and shallow-marine conditions with weak and medium activity of the hydrodynamic regime. In the south-east of the Voronezh Anteclise the formation occurred under lagoon and delta conditions. Explosive volcanic activity was the determining factor of sedimentation in the south-east of the territory.

Conclusions: Yastrebovsk deposits were formed under a warm moist climate with low-amplitude tectonic movements. At this time, the sea transgressed from the east, and ablation of terrigenous material occurred from the south and west. A characteristic feature of the Yastrebovsk deposits is an admixture of pyroclastic material from active volcanoes in the south-east of the territory. These results can be used during geological surveys in the studied area and become the basis for lithological-facie mapping of a scale of 1:200 000 throughout the territory of the Voronezh Anteclise.

Keywords: facies analysis, sedimentogenesis scheme, Yastrebovsk time, coastal marine facies zone, shallow marine facies zone, lagoon, delta, volcanic-sedimentary rocks, ilmenite.

Funding: The study was supported by the Russian Foundation for Basic Research, project no. 18-3500115 mol_a.

For citation: Milash A. V. Lithology and facies of Yastrebovsk deposits of the crestal part of the Voronezh Anteclise. Vestnik Voronezhskogo gosudarstvennogo universiteta. Seriya: Geologiya = Proceedings of Voronezh State University. Series: Geology, 2020, No. 1, pp. 59-65. DOI: https://doi.org/10.17308/geology. 2020. $1 / 2514$

Conflict of interests: The author declares the absence of obvious and potential conflicts of interest related to the publication of this article.

\section{REFERENCES}

1. Milash A. V. The litologo-facial characteristic of jastrebovsky sediments of the southeast of Voronezh antecline. Vestnik Voronezhskogo gosudarstvennogo universiteta. Seriya: Geologiya $=$ Proceedings of Voronezh State University. Series: Geology, 2016, no. 1, pp. 37-43. URL: http://www.vestnik.vsu.ru/pdf/ heologia/2016/01/2016-01-05.pdf (accessed: 14 February 2020). (In Russ., abstract in Eng.)

2. Savko A. D, Manukovski S. V., Mizin A. I., Burikin V. N., Bartenev V. K., Okorokov V. A., Babkin V. F. Litologia I facii doneogenovih onlozhenii Voronezhskoi anteklizi. [Lithologi and facies of the Voronezh anteclise pre-neogene deposites]. Trudy Nauchno-issledovatel'skogo Instituta Geologii [The work of the Research Institute of Geology], Voronezh, VSU Publ., 2001, vol. 3, 201 p. URL: http://ниигвгу.pф/nauchnye-trudy/trudyniig/ (accessed: 14 February 2020). (In Russ., abstract in Eng)

3. Savko A. D. Geologia Voronezhskoi anteklizi. [Geology of the Voronezh Antecline]. Trudy Nauchno-issledovatel'skogo Instituta Geologii [The work of the Research Institute of Geology], Voronezh, VSU Publ., 2002, vol.12, 165 p. http://ниигвгу.pф/nauchnye-trudy/trudy-niig/ (accessed: 14 February 2020). (In Russ.)

4. Kononova L. I., Ovnatova N. S., Rzhosnitskaya M. A., Rodionova G. D., Umnova V. T., Fedorova T. I. Devon Voronezhskoi anteklizi i Moskovskoi sineklizi. [The Devonian of the Voronezh anticline and the Moscow synklin]. Moscow, Komitet RF po geologii i ispolzovanii nedr, 1995, 265 p. URL: http://www.geokniga.org/books/7307 (accessed: 14 February 2020). (In Russ., abstract in Eng)

5. Milash A.V., Savko A.D. Litologia devonskih onlozheniy ugovostoka Voronezhskoy anteclizi. [Lithologi of the Devonian deposits of the south-east of the Voronezh antecline]. Trudy Nauch- no-issledovatel'skogo Instituta Geologii [The work of the Research Institute of Geology], Voronezh, VSU Publ., vol. 100, 2017. 131 p. URL: https://www.elibrary.ru/item.asp?id= 30314171 (accessed: 14 February 2020). (In Russ., abstract in Eng)

6. Kanzerov V. A. Ilmentionosniivulkanogenno-osadochnie porodi pozdnego devona ugo-vostoka Voronezhskoi anteklizi . Dis. kand. geol.-min. nauk [Ilmenitonous volcanic-sedimentary rocks of the late Devonian of the southeast of the Voronezh antecline. Extended Abstract of Ph.D. Thesis]. Kharkiv, 1986. 23 p.

7. Savko A. D, Manukovski S. V., Mizin A. I., Burikin V. N., Bartenev V. K. Objasnitelnaja zapiska $k$ atlasu facialnih kart Voronezhskoi anteklizi. [Explanatory memorandum to the facies maps atlas of the Voronezh anteclise]. Trudy Nauchnoissledovatel'skogo Instituta Geologii [The work of the Research Institute of Geology], Voronezh, VSU Publ., vol. 20, 2004, 107 p. URL: http://ниигвгу.pф/nauchnye-trudy/trudy-niig/ (accessed: 14 February 2020). (In Russ., abstract in Eng)

8. Vinogradov A. P., Nalivkin V. D., Ronov A. B., Hain V. E. Atlas litologo-paleograficheskih kart Russkoy platformi i ee geosinklinalnogo obramlenia. [Atlas of the lithological-paleogeographical maps of the Russian platform and its geosynclinals framing]. M-L.: State Scientific and Technical Publishing House of Literature on Geology and Mineral Protection, 1961. pp. 65-69. 9. Hallam A. Facies interpretation and the stratigraphic record. W. H. Freeman and Co. Oxford. 1981. 304 pp.

10. Milash A.V. Projavlenie vulkanizma v pozdnem devone na jugo-vostoke Voronezhskoy anteklizi. [The manifestation of volcanism in the late Devonian in the southeast of the Voronezh antecline]. Aktualnie problemi dinamicheskoi geologii pri issledovanii platformennih oblastey. Trudi vserossiiskoy nauchnoy konferencii. [Actual problems of dynamic geology in the study of platform areas. Proceedings of the All-Russian Scientific Conference.]. Moscow, May 24-26, 2016. URL: https://istina.msu.ru/collections/21179029/ (accessed 14 February 2020). (In Russ.)
Милаш Алексей Васильевич - к. г.-м. н. , старший преподаватель, Воронежский государственный университет, Воронеж, Российская Федерация; E-mail: pirit86@yandex.ru; ORCID https://orcid.org/0000-0002-2956-3021

Автор прочитал и одобрил окончательный вариант рукописи.
Alexey V. Milash - PhD in Geol.-Min., senior lecturer, Voronezh State University, Voronezh, Russian Federation; E-mail: pirit86@yandex.ru;

ORCID https://orcid.org/0000-0002-2956-3021

Author have read and approved the final manuscript. 